\title{
An Introduction to
}

\section{Metabolic and \\ Cellular Engineering}


This page is intentionally left blank 


\section{An Introduction to Metabolic and Cellular Engineering}

S Cortassa

CONICET, Argentina

M A Aon

CONICET, Argentina

A A Iglesias

CONICET, Argentina

D Lloyd

University of Wales, UK 


\section{Published by}

World Scientific Publishing Co. Pte. Ltd.

P O Box 128, Farrer Road, Singapore 912805

USA office: Suite 1B, 1060 Main Street, River Edge, NJ 07661

UK office: 57 Shelton Street, Covent Garden, London WC2H 9HE

\section{British Library Cataloguing-in-Publication Data}

A catalogue record for this book is available from the British Library.

\section{AN INTRODUCTION TO METABOLIC AND CELLULAR ENGINEERING}

Copyright $\odot 2002$ by World Scientific Publishing Co. Pte. Ltd.

All rights reserved. This book, or parts thereof, may not be reproduced in any form or by any means, electronic or mechanical, including photocopying, recording or any information storage and retrieval system now known or to be invented, without written permission from the Publisher.

For photocopying of material in this volume, please pay a copying fee through the Copyright Clearance Center, Inc., 222 Rosewood Drive, Danvers, MA 01923, USA. In this case permission to photocopy is not required from the publisher.

ISBN 981-02-4835-0

ISBN 981-02-4836-9 (pbk)

Printed in Singapore by Uto-Print 
To Juan Ernesto, Nehuen Quimey, Raul and Pedro. To Gladys (in memoriam). To Francisca, Maris and Juan Carlos. To Miguel (in memoriam). To Silvia. To Norberto (in memoriam). 
This page is intentionally left blank 


\section{Preface}

Metabolic and Cellular Engineering, although as yet only at a beginning, promises huge advances in all fields of the life sciences. The main aim of this book is to introduce students and research workers into this exciting new endeavor. To show a complete picture of the subject, we introduce the main techniques available in the field, in order to point out their power, facilitate their mastery, interpret the achievements already published, and challenge our readers with new problems.

Our own research interests have led us to the elaboration of a wider view on the emergent field of Metabolic Engineering. Thus, here we review the field in order to give a state-of-the-art account. However, in doing this we have selected examples, experiments, and puzzles that, in our opinion, accurately reflect the main advances, achievements, and unsolved problems. So a prospective for the field has also emerged. This book also pretends to be useful to those experimentalists and theoreticians who wish to project themselves into a field that offers great challenges, either experimental or theoretical, for massive integration of the available information.

Until 1960s, metabolic regulation was mainly investigated in isolated and cell-free systems. At present, biotechnology mainly deals with intact cells, and we therefore need to understand how enzymatic reactions behave and are regulated inside the cell. From this standpoint, major limitations arise from the lack of understanding of the behavior of metabolic networks. More precisely; on the one hand, geneticists and molecular biologists produce schemes to explain regulation of gene expression, e.g. by DNA-binding proteins, and on the other hand knowledge of the functioning of metabolic pathways is in some cases fairly complete. However, the link between these two aspects is poorly understood.

Metabolic and Cellular Engineering emphasizes the microorganism (e.g. enzyme function, transport, regulation) and its modification to improve cellular activities, through the use of recombinant DNA. Nevertheless, we assume that the level of performance of the recombinant cells thereby obtained must be evaluated within the context of a specific biotransformation. Thus Metabolic and Cellular Engineering is bred of a powerful alliance of two disciplines: GeneticsMolecular Biology and Quantitative Biochemistry and Physiology. Both are 
driven by continuous refinement of basic understanding of metabolism, physiology, cellular biology (growth, division, differentiation), and the development of new mathematical modeling techniques.

We hope that, even if our aim is minimally attained, then those who have read the book will feel stimulated enough to engage in the field to themselves make new contributions.

The main material of the present book as well as its general structure originated, in part, from a series of lectures given by the authors in the framework of an international course for postgraduate students "Principles of Bioprocess and Metabolic Engineering" supported by the binational centre CABBIO (Centro Argentino-Brasileño de Biotecnología) held at the end of the year 1998 in Chascomús, Buenos Aires. We would like to gratefully acknowledge the participation in that course of Dr. Claudio Voget (Universidad Nacional de La Plata, Argentina) and Dr. Juan Carlos Aon (MIT, USA) for their contribution to the subject of mass and energy transfer and fermentation technology, respectively.

The contribution of the following people for enlightening and useful discussions is gratefully acknowledged: Sam Vaseghi (CITAG, Hamburg, Germany), late Manfred Rizzi (University of Stuttgart, Germany), Marta Cascante (Universitat de Barcelona, Spain), Francesc Mas (Universitat de Barcelona, Spain), Luis Acerenza (Facultad de Ciencias, Uruguay), Carlos E. Argaraña (Universidad Nacional de Córdoba, Argentina), Matthias Reuss (University of Stuttgart, Germany), A.H. Stouthamer (Free University Amsterdam, The Netherlands), Carlos Mignone (Universidad de La Plata, Argentina), Daniel Guebel (Universidad Nacional de Quilmes, Argentina), Nestor V. Torres Darias (Universidad de La Laguna, Spain).

We would also like to express our gratitude for the financial support provided by Fundación Antorchas (ARGENTINA), Centro Argentino Brasileño de Biotecnología (CABBIO), Secretaría de Ciencia y Técnica through the grant ANPCyT PICT"99 1-6074, Facultad de Bioquímica y Ciencias Biológicas (Universidad Nacional del Litoral) and Consejo Nacional de Investigaciones Científicas y Técnicas (CONICET) in Argentina and the Cardiff School of Biosciences, Cardiff University in Wales, United Kingdom.

Chascomús, Buenos Aires Cardiff, Wales November, 2001 


\section{Contents}

Preface vii

List of Abbreviations $\quad$ XV

Introduction $\quad 1$

Introductory Outlines 1

Metabolic and Cellular Engineering in the Context of Bioprocess

$\begin{array}{ll}\text { Engineering } & 2\end{array}$

Tools for Metabolic and Cellular Engineering 3

Engineering Cells for Specific Biotransformations 5

Metabolic Areas that Have Been Subjected to MCE 8

$\begin{array}{lr}\text { From DNA Sequence to Biological Function } & 17\end{array}$

Temporal and Spatial Scaling in Cellular Processes 21

Scaling in Microbial and Biochemical Systems 22

Views of the Cell $\quad 24$

Black and Grey Boxes: Levels of Description of Metabolic Behavior in Microorganisms $\quad 24$

Transduction and Intracellular Signalling $\quad 29$

Self-organized Emergent Phenomena $\quad 30$

Homeodynamics and Coherence $\quad 34$

Matter and Energy Balances $\quad 39$

Mass Balance $\quad 39$

General Formulation of Mass Balance $\quad 40$

Integral and Differential Mass Balances $\quad 41$

Growth Stoichiometry and Product Formation $\quad 42$

Biomass and Product Yields $\quad 46$

$\begin{array}{ll}\text { Electron Balance } & 47\end{array}$

Theoretical Oxygen Demand 48

Opening the "Black Box". Mass Balance as the Basis of
Metabolic Flux Analysis

Energy Balance $\quad 63$

Forms of Energy and Enthalpy 64 
Calorimetric Studies of Energy Metabolism $\quad 67$

Heat of Combustion $\quad 68$

An Energetic View of Microbial Metabolism 73

Cell Growth and Metabolite Production. Basic Concepts 77

Microbial Growth under Steady and Balanced Conditions $\quad 77$

Microbial Energetics under Steady State Conditions $\quad 84$

Growth Kinetics under Steady State Conditions $\quad 85$

The Dilution Rate $\quad 86$

The Dilution Rate and Biomass Concentration 86

The Dilution Rate and the Growth-limiting Substrate Concentration 87

Biomass and Growth-limiting Substrate Concentration at the Steady

State $\quad 88$

Growth as a Balance of Fluxes 91

The Flux Coordination Hypothesis 93

Toward a Rational Design of Cells 96

Redirecting Central Metabolic Pathways under Kinetic or

Thermodynamic Control 97

Thermodynamic or Kinetic Control of Flux under Steady State

Conditions

Kinetic and Thermodynamic Limitations in Microbial Systems.

$\begin{array}{ll}\text { Case Studies } & 102\end{array}$

Saccharomyces cerevisiae 102

Escherichia coli 105

Increasing Carbon Flow to Aromatic Biosynthesis in Escherichia $\begin{array}{ll}\text { coli } & 106\end{array}$

Methods of Quantitation of Cellular "Processes Performance"

Stoichiometry of Growth: The Equivalence between Biochemical

Stoichiometries and Physiological Parameters 111

A General Formalism for Metabolic Flux Analysis $\quad 114$

A Comparison between Different Methods of MFA 115

MFA Applied to Prokaryotic and Lower Eukaryotic Organisms 115

MFA as Applied to Studying the Performance of Mammalian

Cells in Culture

Metabolic Fluxes during Balanced and Steady State Growth 119

Bioenergetic and Physiological Studies in Batch and Continuous

Cultures. Genetic or Epigenetic Redirection of Metabolic Flux 120

Introduction of Heterologous Metabolic Pathways 120

Metabolic Engineering of Lactic Acid Bacteria for Optimising

Essential Flavor Compounds Production 
Metabolic Control Analysis

Summation and connectivity theorems 131

Control and Regulation

The Control of Metabolites Concentration

A Numerical Approach for Control Analysis of Metabolic

Networks and Nonlinear Dynamics

The TDA Approach as Applied to the Rational Design of

Microorganisms: Increase of Ethanol Production in Yeast

Phase I: Physiological, Metabolic and Bioenergetic Studies of

Different Strains of $S$. cerevisiae

Phase II: Metabolic Control Analysis and Metabolic Flux

Analysis of the Strain under the Conditions Defined in Phase I

Phases III and IV: To Obtain a Recombinant Yeast Strain with

an Increased Dose of PFK, and to Assay the Engineered Strain

in Chemostat Cultures under the Conditions Specified in Phase I 140

Appendix A

A Simplified Mathematical Model to Illustrate the Matrix

Method of MCA

Appendix B

Conditions for Parameter Optimization and Simulation of the Mathematical Model of Glycolysis

Dynamic Aspects of Bioprocess Behavior

Transient and Oscillatory States of Continuous Culture 145

Mathematical Model Building

Transfer-Function Analysis and Transient-Response Techniques 151

Theoretical Transient Response and Approach to Steady State 152

Transient Responses of Microbial Cultures to Perturbations of the

Steady State

Dilution Rate

Feed Substrate Concentration

Growth with Two Substrates 156

Temperature 156

Dissolved Oxygen 156

The Meaning of Steady State Performance in Chemostat Culture 157

Oscillatory Phenomena in Continuous Cultures

1. Oscillations as a Consequence of Equipment Artifacts

2. Oscillations Derived from Feedback Between Cells and Environmental Parameters

3. Oscillations Derived from Intracellular Feedback Regulation 159

4. Oscillations Derived from Interactions between Different Species in Continuous Culture

5. Oscillations Due to Synchronous Growth and Division 
Bioprocess Development with Plant Cells

MCE in Plants: Realities and Potentialities

Plant Transformation for Studies on Metabolism and Physiology 172

Improving Plants through Genetic Engineering

Improving Plant Resistance to Chemicals, Pathogens and

Stresses

Improving Quality and Quantity of Plant Products

Using Plant Genetic Engineering to Produce Heterologous Proteins 179

Tools for the Manipulation and Transformation of Plants

Plant Metabolism: Matter and Energy Flows and the Prospects of MCA

Metabolic Compartmentation in Plant Cells

Carbon Assimilation, Partitioning, and Allocation 186

Carbon Fixation in Higher Plants $\quad 188$

MCA Studies in Plants

Regulation and Control: Starch Synthesis, a Case Study 196

Concluding Remarks

Outline

The Global Functioning of Metabolic Networks

The Nature of the Carbon Source Determines the Activation of Whole Blocks of Metabolic Pathways with Global Impact on Cellular Energetics

Carbon Sources that Share Most Enzymes Required to

Transform the Substrates into Key Intermediary Metabolites under Similar Growth Rates, Bring About Similar Fluxes through the Main Amphibolic Pathways

Interaction between Carbon and Nitrogen Regulatory Pathways in $S$. cerevisiae

Flux Redirection toward Catabolic (Fermentation) or Anabolic (Carbohydrates) Products May Be Generated as a Result of Alteration in Redox and Phosphorylation Potentials

Temperature-Dependent Expression of Certain Mutations

Depend upon the Carbon Source

There Seems to Exist a General Pattern of Control of the

Intracellular Concentration of Metabolites

Dependence of the Control of Glycolysis on the Genetic

Background and the Physiological Status of Yeast in Chemostat Cultures 
Metabolites and Macromolecules as Targets for Cellular Engineering

Catabolite Repression and Cell Cycle Regulation in Yeast

The Selective Functioning of Whole Metabolic Pathways Is

Index 
This page is intentionally left blank 


\section{List of Abbreviations}

$\begin{array}{ll}\text { AcCoA } & \text { acetyl Coenzyme A } \\ \text { ADPGlc } & \text { ADP glucose } \\ \text { ADPGlcPPase } & \text { ADP glucose pyrophosphorylase } \\ \alpha \text { KG } & \alpha \text { ketoglutarate } \\ \text { ADH } & \text { alcohol dehydrogenase } \\ \text { ATPase } & \text { ATP hydrolase } \\ \text { BST } & \text { Biochemical system theory } \\ \text { CDC } & \text { cell division cycle } \\ \text { CER } & \text { CO2 evolution rate } \\ \text { CSTR } & \text { continuously stirred tank reactor } \\ \text { CAM } & \text { crassulacean acid metabolism } \\ \text { 2DG } & \text { 2-deoxyglucose 2DG } \\ \text { DAHP } & \text { 3-deoxy-D-arabino-heptulosonate-7-phosphate } \\ \text { DHAP } & \text { dihydroxyacetone-P } \\ \text { D } & \text { dilution rate } \\ \text { DBA } & \text { Dynamic bifurcation analysis } \\ \text { E4P } & \text { erythrose 4 phosphate } \\ \text { EPSP } & \text { 5-enolpyruvylshikimate-3-phosphate } \\ C_{E k}^{J i} & \text { Flux control coefficient } \\ \text { FCH } & \text { Flux coordination hypothesis } \\ \text { FBPase } & \text { fructose-1,6-bisP phosphatase } \\ \text { G6P } & \text { glucose 6 phosphate } \\ \text { GAP } & \text { glyceraldehyde-3P } \\ \text { GC/MS } & \text { gas chromatography/mass spectrometry } \\ \text { GAPDH } & \text { glyceraldehyde 3 phosphate dehydrogenase } \\ \text { HK } & \text { hexokinase } \\ \mathrm{K}_{\mathrm{m}} & \text { Michaelis Menten constant in enzyme kinetics } \\ \text { MCE } & \text { Metabolic and cellular engineering } \\ \text { MCA } & \text { Metabolic control analysis } \\ \text { MFA } & \text { Metabolic flux analysis } \\ C_{E k}^{M i} & \text { Metabolite concentration control coefficient } \\ \mu & \text { growth rate } \\ \text { MTP } & \text { microtubular protein } \\ & \\ & \end{array}$


$\mathrm{m}_{\mathrm{S}}$

NMR

NADP GDH

OAA

ODE

OUR

PP pathway

PEP

PEPCK

PEPCase

PFK

PGI

3PG or 3PGA

PGK

PGM

PTS

PEG

PY

$\mathrm{qCO} 2$

$\mathrm{qEtOH}$

qGlc

qO2

R5P

RPPP

RQ

$\mathrm{Cp}$

TP

TDA

TCA cycle

$V_{\max }$

$Y_{\text {ATP }}$

$\mathrm{Y}_{\mathrm{O} 2}$

$Y_{\mathrm{PC}}$

$\mathrm{Y}_{\mathrm{XC}}$ or $\mathrm{Y}_{\mathrm{XS}}$

$\gamma_{B}$

$\gamma_{s}$ maintenance coefficient

nuclear magnetic resonance

NADP dependent glutamate dehydrogenase

oxalacetate

ordinary differential equations

oxygen uptake rate

pentose phosphate pathway

phosphoenolpyruvate

phosphoenolpyruvate carboxy kinase

phosphoenolpyruvate carboxylase

phosphofructokinase

phosphoglucoisomerase

3 phosphoglycerate

phosphoglycerokinase

phosphoglyceromutase

phosphotransferase system

polyethylene glycol

pyruvate

specific rate of carbon dioxide production

specific rate of ethanol production

specific rate of glucose consumption

specific rate of oxygen consumption

ribose 5 phosphate

reductive pentose phosphate pathway

respiratory quotient

specific heat

triose phosphate

Transdisciplinary approach

tricarboxylic acid cycle

maximal rate in enzyme kinetics

yield of biomass on ATP

yield of biomass on oxygen

yield of product on carbon substrate

yield of biomass on carbon substrate

degree of reduction of biomass

degree of reduction of substrate 